\title{
Psicologia ambiental: entendendo as relações do homem com seu ambiente ${ }^{1}$
}

\author{
Environmental psychology: a human and \\ environment relationship comprehension
}

\author{
Luciana Silva Martins de SOUZA
}

A Psicologia Ambiental é uma área de conhecimento da Psicologia que se interessa pelo homem inserido num contexto físico e social, e tem como objetivo o estudo dos aspectos individuais e coletivos das inter-relações entre o homem e o seu ambiente.

Nesse livro, os organizadores conseguiram reunir uma diversidade de trabalhos da Psicologia Ambiental muito interessante, pois dá ao leitor uma idéia da abrangência dos temas abordados por essa área recente e, ainda, tão pouco conhecida.

Hartmut Günther é doutor em Psicologia Social e professor titular no departamento de Psicologia Social e do Trabalho da Universidade de Brasília (UnB). Realiza pesquisas sobre ambientes de trânsito e qualidade de vida urbana no Laboratório de Psicologia Ambiental da UnB. José Q. Pinheiro é doutor em Psicologia Ambiental, professor do curso de Psicologia e do programa de pós-graduação em Psicologia da Universidade Federal do Rio Grande do Norte (UFRN), e coordenador do Grupo de Estudos Inter-Ações Pessoa-Ambiente e da Rede de Psicologia Ambiental Latino-Americana (REPALA). Raquel Souza Lobo Guzzo é doutora em Psicologia Escolar, docente do curso de Psicologia e do programa de pós-graduação em Psicologia da Pontifícia Universidade Católica de Campinas (PUC-Campinas), e coordenadora do Grupo de Pesquisa Risco à Proteção - Intervenção Preventiva em Comunidades.
O livro é composto por uma apresentação e de nove capítulos distribuídos em duas partes. O objetivo da primeira parte é esclarecer o que se entende por ambiente e quais as relações que ele possui com a percepção e a constituição humana. A segunda parte engloba reflexões a respeito dos aspectos envolvidos no processo de interação humano-ambiental. Cada capítulo trata de um trabalho específico realizado na área pelo respectivo autor.

O livro foi escrito por psicólogos pós-graduados - mestres e doutores em diferentes áreas da Psicologia - que atuam como pesquisadores e integram, na sua maioria, o corpo docente de diferentes universidades do Brasil (UnB, UFRN, PUC-Campinas, Universidade de São Paulo, Universidade de Fortaleza), do México e do Chile. Esse diálogo entre as diferentes universidades confere à obra uma dimensão de intercâmbio e enriquece o novo ramo de conhecimento da Psicologia. Nas últimas páginas, podem ser encontrados os dados das trajetórias profissionais de cada um dos autores e seus respectivos endereços para correspondência.

Na apresentação - intitulada "Psicologia ambiental:área emergente ou referencial para um futuro sustentável?" -, os organizadores definem conceitualmente a Psicologia Ambiental e a situam historicamente, fazendo uma breve e concisa análise da sua

\section{VरV}

1 Günter, H., Guzzo, R. S. L., \& Pinheiro, J. Q. (Orgs.). (2004). Psicologia ambiental: entendendo as relações do homem com seu ambiente. Campinas: Alínea.

2 Bolsista do CNPq e Mestranda em Psicologia Social, Programa de Estudos Pós-Graduados em Psicologia Social, Pontifícia Universidade Católica de São Paulo. Rua Ministro Godói, 969, 4ªndar, Bloco A, Sala 4E-10, Perdizes, 05015-901, São Paulo, SP, Brasil. E-mail: <lusmsouza@hotmail.com>. 
consolidação no tempo. Na continuação do texto, eles apresentam a estrutura da obra e deixam claro o objetivo central do livro: difundir entre os profissionais da América Latina - dentro e fora das escolas de Psicologia e áreas correlatas - os conceitos de homem e mundo adotados pela Psicologia Ambiental. Essa apresentação é muito importante pelo seu caráter informativo, pois apresenta ao leitor não apenas a obra mas também toda a área para a qual ela pretende contribuir.

Na primeira parte do livro, o capítulo de Marcos Ribeiro Ferreira condensa os motivos que impulsionam a participação da Psicologia no contexto ambiental global. O autor enfoca a situação de degradação ambiental destas últimas décadas, advinda do padrão vigente de exploração da natureza, ao lado do descomprometimento com a preservação ambiental. Revela que para estudiosos e pesquisadores ambientais uma nova racionalidade ambiental precisaria ser constituída. A partir daí, o autor entra na questão do que denomina "validação ecológica", que consiste na idéia de que os objetos de pesquisa definidos sejam algo que tenha realmente relevância na vida cotidiana das pessoas.

No segundo capítulo, os autores Fernando Olguín e Carlota Reyes-Lira propõem a utilização de técnicas da Gestalt-Terapia e de métodos da pesquisa qualitativa para o estudo da interação entre o indivíduo e seu meio. Para isso, utilizam-se idéias desenvolvidas por González Rey, Zemelman, Jiménez Domínguez e outros. Para os autores, a Gestalt pressupõe que o pesquisador de questões ambientais seja parte integrante do ambiente estudado; e como a análise qualitativa deve abordar a subjetividade, é feita uma proposta gestáltica de inserção do pesquisador no meio. O interessante do exercício proposto pelos autores reside na possibilidade do pesquisador reconhecer sua própria posição na pesquisa e a carga ideológica que isso envolve.

Na segunda parte do livro, o terceiro capítulo aborda análises das transformações no modo de vida ¿ 3 advindas com a urbanização do bairro Barra Funda de 乞 São Paulo. Elaine Rabinovich, autora do capítulo, N apresenta as etapas de um estudo de caso baseado na pergunta: quais as conseqüências para o desenvolvimento humano da substituição de um espaço livre 204 de locomoção/deslocamento por um espaço segmentado e permanentemente controlado pelo adulto?

O capítulo seguinte se baseia nas discussões recentes sobre a reformulação do Plano de Prevenção e Descontaminação Atmosférica da Região Metropolitana, formulado pela Comissão Nacional do Meio Ambiente do Chile. Essa se configura como uma importante discussão nacional, pois se desenvolve de forma participativa, envolvendo diferentes setores da sociedade. No artigo, Pablo Jara e Emilio Moyano Díaz destacam de que forma se dá a participação do psicólogo no âmbito da Educação Ambiental.

No capítulo cinco, os autores Patricia Andeane, Eric Rosas e Cesáro Rodríguez apresentam um estudo analítico das propriedades espaciais do cenário associadas aos padrões de uso dos espaços pelas pessoas. Para isso utilizaram o modelo da Sintaxis Espacial, detalhadamente explicado no decorrer do capítulo, que pode contribuir com ferramentas objetivas e precisas para a análise de cenários e a avaliação da conduta espacial humana.

No sexto capítulo, Sylvia Cavalcante apresenta um estudo fenomenológico da natureza da porta, revelando as representações psicológicas e implicações psicossociais que as funções físicas de uma porta podem assumir nas interações humanas. Embora o tema possa gerar certa estranheza para o leigo, é muito interessante acompanhar as análises tecidas pela autora, ao longo do relato, a respeito de expressões de necessidades, desejos e poder.

O sétimo capítulo é dedicado à participação do jovem nos estudos de Psicologia Ambiental, enfocando o ponto de vista mais freqüente sobre ele e o ambiente com o qual ele interage. Para isso, Isolda Günther e Ludmila Cunha estabeleceram questões que orientaram a análise de cinco textos de Psicologia Ambiental (de diferentes autores), e de uma amostragem do periódico Children's Environments, publicado pela Universidade de Nova lorque.

No oitavo capítulo, José Q. Pinheiro analisa experiências relativas à apropriação de espaços, considerando que ela se constitui a partir da percepção e conseqüente cognição dos mesmos. O objetivo do autor é abordar as experiências de ambientes vividas a partir de apresentações trazidas por outrem, ou seja, 
quando não há contato direto com o fenômeno ou situação. Esses ambientes, aos quais não se tem acesso diretamente, são denominados "ambientes de segunda mão" e é justamente neles que as pessoas se relacionam em grande parte da vida.

O nono e último capítulo demonstra a integração entre a Psicologia Ambiental e a Psicologia do Desenvolvimento a partir de estudos desenvolvidos sobre a relação entre a organização do espaço e sua utilização por grupos de crianças em creches. Essas pesquisas adotaram o referencial da abordagem ecológica para o desenvolvimento humano, representada, principalmente, por Urie Bronfenbrener. Mara Campos-de-Carvalho parte do pressuposto de que tanto os aspectos físicos ambientais quanto os sociais influenciam de maneira significativa o desenvolvimento humano, que decorre das experiências de interações humano-ambientais. A autora apresenta o método utilizado pelas pesquisas de experimento ecológico, que envolve a seleção do aspecto físico que se pretende investigar e a manipulação sistemática da variável em estudo, mantendo tão estável quanto possível a posição dos demais elementos do espaço.

Pode-se ver pelo livro que se trata de uma área dinâmica que tem atraído estudiosos e pesquisadores de Psicologia de diferentes instituições, áreas de atuação, abordagens e trajetórias. Por outro lado, essa diversidade temática e metodológica é apontada pelos autores como um dos fatores que dificultam o desenvolvimento desse ramo de conhecimento, pois são poucas as produções que se identificam como sendo "de Psicologia Ambiental". A variedade e a amplitude características da obra podem confundir o leitor que nunca teve contato com a área. As delimitações desse campo de conhecimento ainda não são muito claras, mais por motivos de consolidação do próprio campo do que pela forma como a obra o trata. Como afirmam os organizadores desse livro, na América Latina a caminhada está apenas começando.

Recebido em: 27/6/2005

Versão final reapresentada em: 7/11/2005

Aprovado em: 22/11/2005 
